
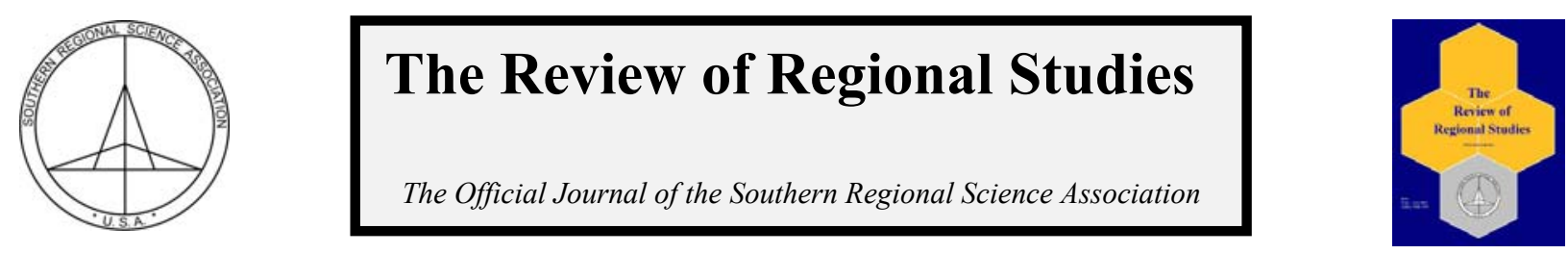

\title{
A Regime-Switching Analysis of the Impact of Oil Price Changes on the Economies of U.S. States ${ }^{*}$
}

\author{
Wei Kang, ${ }^{a}$ David A. Penn, ${ }^{b}$ Joachim Zietz ${ }^{\mathrm{c}}$ \\ ${ }^{a}$ Regional Economic Models, Inc. (REMI), USA \\ ${ }^{b}$ Business and Economic Research Center and Economics and Finance Department, \\ Middle Tennessee State University, USA \\ ${ }^{c}$ Economics and Finance Department, Middle Tennessee State University, USA; \\ and EBS Business School, EBS Universität für Wirtschaft und Recht, Wiesbaden, Germany
}

\begin{abstract}
The study employs quarterly data from 1958:I to 2010:IV to analyze how state earnings respond to oil price changes. We allow for asymmetric and nonlinear reactions of state earnings through a smooth regime switching model. Thirteen of the 50 states are best modeled with a two regime model. The response of the remaining states can be adequately captured by a linear least squares model. The estimation results show marked differences among states in both the tolerance and the delay of response to an oil price change. The speed at which the transition occurs across regimes varies significantly by state.
\end{abstract}

Keywords: state earnings growth, oil prices, asymmetry, STAR model

JEL Codes: R11, Q43

\section{INTRODUCTION}

It is generally acknowledged that oil price shocks have asymmetric effects on the economy. An increase in the price of oil is usually followed by a recession, while a major decline in oil prices does not lead to a comparable economic expansion. The study of asymmetric effects of oil price changes can be traced back to Mork (1989), and there are many studies offering different theoretical and empirical analyses regarding the asymmetry or the nonlinear relationship between oil price and the economy (Lee et al. 1995, Cuñado et al. 2003, Hamilton 2003, Penn 2006, and Kilian 2008).

A recent study by Huang (2008) extends the existing literature by examining how a positive oil price shock affects the tolerance and the speed of response of 21 economies. The 21 countries are different in the degree of economic development, energy dependence, and efficiency of energy use. For each country, Huang (2008) estimates both the threshold level at which the country responds to an oil shock and the time delay of the response. From the different responses across countries Huang (2008) concludes that countries with a larger per capita GDP

\footnotetext{
* The authors thank the editors and referees for numerous helpful comments.

Kang is Regional Economist at Regional Economic Models, Inc. Penn is Associate Professor of Economics, Department of Economics and Finance, and Director, Business and Economics Research Center, Middle Tennessee State University. Zietz is Professor of Economics, Department of Economics and Finance, Middle Tennessee State University. Corresponding Author: J. Zietz E-mail: joachim.zietz@mtsu.edu.
}

(C) Southern Regional Science Association 2012.

ISSN 1553-0892, 0048-749X (online)

www.srsa.org/rrs 
tend to have a lower ratio of energy use and, therefore, greater tolerance to a positive oil-price change. The same countries will also take longer to respond to an oil price shock.

This paper studies the tolerance and the speed of adjustment of U.S. state economies to oil price changes. As there are significant differences in the economic development, industrial structure, and energy dependence among the states, we expect to find different responses to an oil price shock.

In contrast to Huang (2008), this study employs a regime-switching approach of the smooth transition autoregressive (STAR) type. Instead of assuming instantaneous regime switching, the STAR model allows for a gradual transition between regimes. Regime-switching models of this type have been applied to a wide range of research on such topics as business cycles (Teräsvirta and Anderson, 1992), stock market (Liu et al., 2005), inflation (Amisano and Fagan, 2010) and real estate (Füss, Stein, and Zietz, 2012).

The remainder of the paper is organized as follows. Section 2 presents the regimeswitching model and the estimation methodology. Section 3 describes the data, and Section 4 discusses the estimation results. Section 5 concludes.

\section{MODEL}

Over time, regime-switching models have evolved into different forms. The form used in Huang (2008) is a two-regime TAR model, which assumes that the model switches instantaneously once an oil price shock passes a threshold value. When the oil price change is below the threshold, it has little influence on the economy; once the oil price change exceeds the threshold, it becomes an essential factor that drives economic activity.

The TAR model ignores cases in which there are more than two regimes and cases in which the transition between regimes occurs smoothly. This study employs the smooth transition autoregressive (STAR) model, which is a regime-switching model that removes these restrictions.

The standard STAR model contains both a linear and a nonlinear term,

$$
\begin{aligned}
y_{t}= & \left(\alpha^{l}+\sum_{i=1}^{p} \beta_{i}^{l} y_{t-i}+\sum_{k=1}^{K} \sum_{j=1}^{q} \delta_{k, j}^{l} x_{k, t-i}\right) \\
& +\left(\alpha^{n}+\sum_{i=1}^{p} \beta_{i}^{n} y_{t-i}+\sum_{k=1}^{K} \sum_{j=1}^{q} \delta_{k, j}^{n} x_{k, t-i}\right) G(\cdot)+\varepsilon_{t}, \quad t=1 \ldots T
\end{aligned}
$$

where $y_{t}$ represents state real earnings and where $X_{t}$ is a vector of exogenous variables, which includes oil price $\left(o_{t}\right)$, interest rate $\left(r_{t}\right)$, stock prices $\left(s_{t}\right)$, and a spatial lag variable $\left(\right.$ spatial $\left._{t}\right) . G(\cdot)$ stands for the transition function and $\varepsilon_{t}$ is an error term. Superscript $l$ denotes the coefficients of the linear part of the model, while superscript $n$ denotes the coefficients of the nonlinear part. The linear part of the model in the first parenthesis term of Equation (1) takes the form of an autoregressive distributed lag (ARDL) model. It makes a state's earnings depend on earnings in the past periods and the past values of the oil price, interest rates, the spatial variable, and the stock price. Interest rates reflect the influence of monetary policy, while stock prices reflect the increasingly important role of financial wealth in the economy. All the variables used in this study are in the form of growth rates.

(C) Southern Regional Science Association 2012. 
The spatial lag variable takes into account lagged correlation with the earnings of adjacent states. Spatial for a given state is the weighted average of the earnings growth rates for adjacent states, using current real earnings as the weight. The spatial variable for Hawaii is the weighted average growth rate for Washington, Oregon, and California. The spatial variable for Alaska is the weighted average growth rate for the oil-producing states Oklahoma, Louisiana, and Texas.

The nonlinear part of Equation (1) consists of the product of the second parenthesis term, which is again in the form of an ARDL with potentially the same variables as before, and the nonlinear function $G(\cdot)$.

The term $G(\cdot)$ is a transition function, governing the movement from one regime to another. Following Teräsvirta (2004), the general logistic transition function can be written as

$$
G\left(\gamma, c, h_{t}\right)=\left(1+\exp \left\{-\gamma \prod_{k=1}^{N}\left(h_{t}-c_{k}\right)\right\}\right)^{-1}, \quad \gamma>0
$$

where $\gamma$ is the adjustment parameter determining the speed of transition between regimes, $N$ is the number of transition points, $h_{t}$ is the transition variable, which in this study is the oil price change $o_{t-d} ; d$ denotes the delay in the economy's response to changes in oil price, and $c_{k}$ is the threshold value indicating the level of the oil price change at which a transition point occurs. ${ }^{1}$ When the transition variable changes, the value of the transition function moves smoothly between 0 and 1; $\gamma$ controls the slope of the transition function and the location of the thresholds. The most common choices for the value of $N$ are $N=1$ and $N=2$. If $N=1$, the transition occurs monotonically; if $N=2$, the transition path will be symmetric around the midpoint of $\left(c_{1}+c_{2}\right) / 2$ where the value of the transition function is minimized.

There are three types of models nested in the general logistic transition function in equation (2). First, when $\gamma=0, G(\cdot)=1 / 2$, so the STAR model in equation (2) becomes a linear model. Second, when $N=1$, the STAR model is termed an LSTR1 model (Teräsvirta 2004). In this case, the model transitions monotonically from one extreme regime to the other. An LSTR1 model can be used to capture asymmetric behavior in time series. When $h_{t-d}$ moves from $-\infty$ to $\infty, G(\cdot)$ transits smoothly from 0 to 1 . When $h_{t-d}=c, G(\cdot)=1 / 2$. Third, when $N=2$, the STAR model becomes an LSTR2 model. The LSTR2 model can be used to model dynamic behavior when the process is similar at the outer edges of the transition variable. In this case, when the transition variable $h_{t-d}$ is at $-\infty$ and $\infty$, the transition function is $G(\cdot)=1$.

When $\gamma \rightarrow \infty$, the LSTR1 model approaches an instantaneous regime-switching model, while the LSTR2 model will result in a three-regime-switching regression model (Teräsvirta 2004). A STAR model nests the two-regime instantaneous TAR model as a special case: when $N=1$ and the value of $\gamma$ is large, the model becomes a two-regime TAR model as in Huang (2008).

\footnotetext{
${ }^{1}$ Since this study focuses on the state economy's response to oil price changes, only oil price changes and their lag are chosen as possible transition variables to be tested. In general cases, a plausible transition variable can be any endogenous or exogenous variable or its lags.
}

(C) Southern Regional Science Association 2012. 
Since states differ from each other in the level of economic development and the degree of dependence on oil, they will likely experience different tolerances and delays of adjustment to an oil price change. A regime-switching model allows the dynamic movement of a state economy to depend on the oil price variable. In our case, the response of a given state's economy to an oil price shock is divided into different regimes. An oil price shock is compared to one or two threshold values. The differences between the oil price change and the threshold values determine how a state economy will adjust to an oil price change. This threshold value $c$ can be interpreted as the tolerance of an economy to an oil shock. A higher value of $c$ would indicate that the oil price needs to increase by a significant percentage value to trigger a regime change. That would be indicative of an economy that is relatively tolerant to oil price changes.

To estimate a STAR model, the first step is to test for linearity. The testing is complicated because the autoregressive lag order $p$, the delay variable $d$, and the threshold value $c$ are not determined. Various methods exist in the literature to estimate these three parameters. Franses and Van Dijk (2000) demonstrate an example in which they search for two oil price variable candidates with all possible lag lengths $d$ as well as $p$ and select the threshold variable that minimizes the Akaike Information Criterion (AIC). This method is most useful when the choices of $p$ and $d$ depend on each other (Enders 2004). However, it raises the difficulty of estimation when the threshold value $c$ is not known.

As an alternative, Enders (2004) illustrates a technique in which the best-fitting autoregressive lag order $p$ is selected first. He suggests that one should start by estimating a simple linear model in order to fix the data-generating lag process: that is, to choose the AR $(p)$ process. Following Enders (2004), this study first estimates a simple linear AR ( $p$ ) model such that

$$
y_{t}=\alpha+\sum_{i=1}^{p} \beta_{i} y_{t-i}+\eta_{t}
$$

where $\alpha$ is a constant, $\beta_{i}$ represents coefficients of the lags of state earnings, and $\eta_{t}$ is the error term. Equation (3) is estimated in order to choose the lag order $p$. By searching over $p=1, \ldots p^{*}$ one can choose the best-fitting $p^{2}$ by examining the $t$-values of each coefficient, the F-test on a group of coefficients, or the minimum AIC and BIC (Bayesian Information Criterion). ${ }^{3}$ After determining the best-fitting $p$, we estimate the model with only the linear part in equation (1) to test plausible combinations of the exogenous variables and their lags, which are used as the initial setup in the linearity test discussed next.

This study follows Luukkonen, Saikkonen, and Teräsvirta (1988) and Teräsvirta (2004) to test linearity. To accomplish this, the transition function $G(\cdot)$ is replaced by a Taylor series approximation. ${ }^{4}$ Teräsvirta (2004) suggests not omitting lags shorter than the maximum lag of the endogenous variable that is selected by the linear model for the reason that gaps in the lag

\footnotetext{
${ }^{2} p^{*}$ is the maximum possible value of $p$. Since quarterly data are used in this model, 8 is used as the maximum number of $p$, which allows the autoregressive impact for two years.

${ }^{3}$ Franses and Van Dijk (2000) proposed a way to determine $p$ by minimizing the AIC. However, according to Teräsvirta (1994), experience indicates that the indication of the Bayesian BIC is more suitable than the AIC. Thus, when the AIC and BIC indicate different best-fitting lag lengths, this study chooses the one that is indicated by BIC.

${ }^{4}$ The JMulTi software package incorporates this method and is used for the analysis that follows.
}

(C) Southern Regional Science Association 2012. 
structure may reduce the power of the linearity test. This linearity test will help to determine the transition variable as well as the type of STAR model.

(C) Southern Regional Science Association 2012. 
Equations (1) and (2) can be rewritten in a simplified form as

$$
y_{t}=\boldsymbol{\varphi}^{\prime} \mathbf{z}_{\mathbf{t}}+\boldsymbol{\theta}^{\prime} \mathbf{z}_{\mathbf{t}} G(\cdot)+\varepsilon_{t}, \quad t=1 \ldots T
$$

where $\boldsymbol{\varphi}$ and $\boldsymbol{\theta}$ are the vectors of parameters for the linear part and the nonlinear part, respectively, and where $\mathbf{z}_{\mathbf{t}}$ denotes the vector of the lagged endogenous and the exogenous variables. Based on this form, the linearity test can proceed by approximating the transition function in equation (2) with a third-order Taylor expansion around the null hypothesis $\gamma=0$. The approximation yields the following auxiliary regression:

$$
y_{t}=\boldsymbol{\rho}_{0}^{\prime} \mathbf{z}_{\mathbf{t}}+\sum_{l=1}^{3} \boldsymbol{\rho}_{\mathbf{1}}^{\prime} \tilde{\mathbf{z}}_{\mathbf{t}} h_{t}^{l}+\varepsilon_{t}^{*}, \quad t=1 \ldots T
$$

where $h_{t}$ is the transition variable raised to the power $l$, and $\varepsilon_{t}^{*}$ is the error term.

The null hypothesis for testing for linearity is $H_{0}: \rho_{1}=\rho_{2}=\rho_{3}=0$. The F-statistic is used to determine the test result. The linearity test is conducted using all reasonable lags of our transition variable, the oil price change, one at a time; we choose the lag for which the null is rejected. If the null hypothesis is rejected for more than one lag, we select the lag with the lowest $p$-value from the $F$-test.

If linearity is rejected and the lag of the transition variable is determined, we proceed to select the type of STAR model, either LSTR1 or LSTR2. The selection of the model type is also based on equation (5). Teräsvirta (1994) suggests the following tests in sequence:

1. $\mathrm{H}_{04}: \rho_{3}=0$.

2. $\mathrm{H}_{03}: \rho_{2}=0 \mid \rho_{3}=0$.

3. $\mathrm{H}_{02}: \rho_{1}=0 \mid \rho_{2}=\rho_{3}=0$.

If the test of $\mathrm{H}_{03}$ yields the lowest p-value, we choose an LSTR2 model; otherwise, we opt for an LSTR1 model. ${ }^{5}$ Once the transition variable is selected and the model type is determined, the next stage is to estimate the parameters in the STAR model using conditional maximum likelihood.

\section{DATA}

Due to the lack of quarterly state output data, quarterly private earnings from the Bureau of Economic Analysis (BEA) are used as a proxy for state quarterly GDP. We employ quarterly data from 1958:I to 2010:IV, deflated by the PCE deflator from BEA. The BEA price index data for gasoline and oil is used as the oil price variable, deflated by the GDP deflator. The federal funds rate is our measure of the interest rate. The quarterly federal funds rate is averaged from monthly data obtained from the Federal Reserve. The stock price variable is the average of daily closing price from the Standard and Poor's 500 Index (S\&P 500), deflated by the CPI. The S\&P 500 Index comes from FRED, and the CPI from the Bureau of Labor Statistics. All variables used in the models are first differences in logs, except for the interest rate, which is in first differences.

${ }^{5}$ The linearity test, model selection, and nonlinear estimation in this study are done using JMulTi.

(C) Southern Regional Science Association 2012. 
The modeling process detailed in the last section is carried out for each of the 50 states separately. However, to allow for spatial autocorrelation among neighboring states we include a spatial lag variable. We anticipate that states with a higher level of economic development and less dependence on oil are likely to exhibit stronger tolerance and longer delays in their response to an oil price shock.

The highest rates of earnings growth tend to occur in the sunbelt and mountain states: Nevada, Arizona, Alaska, Florida, and Colorado comprise the five fastest-growing states. Alaska has a much higher standard deviation in economic growth than the other states, with both the highest and lowest growth rates. ${ }^{6}$

\section{RESULTS}

\subsection{Linear Analysis}

As mentioned in Section 2, for each state, we use the autoregressive distributed lag (ARDL) model of equation (1) to test for the best-fitting lag length for the endogenous variable and combinations of the exogenous variables. All the lags, up to the maximum lag of the endogenous variables, are kept in this step in order to avoid reducing the power of the nonlinear test later on. We use the Akaike Information Criterion (AIC) and the Bayesian Information Criterion (BIC) to evaluate the models. When AIC and BIC reach minima at different lag lengths, we follow the BIC. The maximum lag of the endogenous and exogenous variables considered is eight. The results from the linear model are used as the starting point of the nonlinear analysis.

The lag of the spatial variable is a key predictor of a state's earnings, for both the linear and nonlinear portions of the model. Correlations between the lagged spatial variable and earnings average 0.25 across the states, ranging from 0.43 for Georgia to 0.0 for Alaska.

\subsection{Nonlinear Analysis}

The steps discussed in Section 2 are followed for each state to test for nonlinearity and for the appropriate type of nonlinear model (LSTR1 or LSTR2). Test results are presented in Table 1.

The results show that 10 of the 50 states should be modeled with the LSTR1 model and three with the LSTR2 model. Of the 50 states, 37 show no sign of nonlinearity and, therefore, do not require more than a linear ARDL model. We will not consider these states any further in this study. ${ }^{7}$

The lag lengths of the oil price variable indicate how fast a state responds to an oil price change. Table 1 shows that the response is delayed from 0 to 8 quarters. In eight of the thirteen states, eight quarters pass for an oil price change to have full effect. For two states (Texas and Washington) the effect occurs with no lag, while two states (North Carolina and Oklahoma) experience lags of four and three quarters respectively. The lag for Wyoming is seven quarters. The oil-producing states of Oklahoma and Texas experience much shorter lags compared with the oil-consuming states, with the exception of Washington.

\footnotetext{
${ }^{6}$ Detailed summary statistics for all states are available from in Appendix A1.

${ }^{7}$ Alaska and Hawaii were modeled with and without the lagged spatial variable. Nonlinearity was rejected for all variations.
} 
The two essential parameters in the STAR model are the slope parameter $\gamma$ and the critical value of the transition variable $c$. Georgia, Minnesota, and Texas fit the LSTR2 model best, so these states have a second threshold value ( $c 2)$. Table 2 shows estimates of $\gamma$ an $c$ from the best-fitting LSTR1 and LSTR2 models for the 13 states over the period 1958:I to 2010:IV. ${ }^{8}$ The results show strong evidence of a significant asymmetric relationship between oil price changes and state earnings. The estimates of $\gamma$ are significant for all thirteen states, as are the estimated threshold values of the transition variables $c$ and $c 2$. The results reveal substantial diversity for both of these two essential parameters across states.

Figures 1 to 4 present plots of the transition functions $G(\cdot)$ against the transition variables $\left(h_{\mathrm{t}}\right)$. The shapes and positions of the transition functions are largely determined by the values of the adjustment parameter $\gamma$ and the critical values of the transition variables $c$ and $c 2$. Figures 1 to 3 include states with a single threshold (LSTR1 models), while Figure 4 includes three states that have two thresholds (LSTR2 models). Figure 1 consists of Arkansas, a state that is typically in the linear regime $(G=0)$. The fact that the nonlinear regime is rarely relevant for Arkansas results from a critical value $c$ that is positive and relatively large. Since the oil price change rarely rises beyond this high value, the nonlinear regime becomes active only in extraordinary circumstances.

Figure 2 shows seven states for which the nonlinear regime $(G=1)$ is typically active. All of these states have negative critical values $(c)$. Since the oil prices typically change by more than the critical values, the nonlinear regime is active for these states most of the time.

Table 1: Tests of Linearity for State Earnings

\begin{tabular}{lcccccc}
\hline \hline \multicolumn{1}{c}{ State } & $\begin{array}{c}\text { Transition } \\
\text { Variable }\end{array}$ & $H_{0}$ & $H_{04}$ & $H_{03}$ & $H_{02}$ & $\begin{array}{c}\text { Suggested } \\
\text { Model }\end{array}$ \\
\hline Alabama & $\mathrm{o}(\mathrm{t}-8)$ & 0.0002 & 0.0396 & 0.0247 & 0.0033 & LSTR1 \\
Arkansas & $\mathrm{o}(\mathrm{t}-8)$ & 0.0024 & 0.0272 & 0.3191 & 0.0054 & LSTR1 \\
Georgia & $\mathrm{o}(\mathrm{t}-8)$ & 0.0002 & 0.0111 & 0.0044 & 0.0691 & LSTR2 \\
Maryland & $\mathrm{o}(\mathrm{t}-8)$ & 0.0036 & 0.0006 & 0.1486 & 0.6170 & LSTR1 \\
Minnesota & $\mathrm{o}(\mathrm{t}-8)$ & 0.0042 & 0.4633 & 0.0001 & 0.5947 & LSTR2 \\
Missouri & $\mathrm{o}(\mathrm{t}-8)$ & 0.0000 & 0.0002 & 0.0267 & 0.0059 & LSTR1 \\
New York & $\mathrm{o}(\mathrm{t}-8)$ & 0.0000 & 0.0002 & 0.0050 & 0.0708 & LSTR1 \\
North Carolina & $\mathrm{o}(\mathrm{t}-4)$ & 0.0001 & 0.0032 & 0.0215 & 0.0316 & LSTR1 \\
Oklahoma & $\mathrm{o}(\mathrm{t}-3)$ & 0.0003 & 0.0164 & 0.0615 & 0.0070 & LSTR1 \\
Texas & $\mathrm{o}(\mathrm{t})$ & 0.0002 & 0.1216 & 0.0004 & 0.0348 & LSTR2 \\
Virginia & $\mathrm{o}(\mathrm{t}-8)$ & 0.0000 & 0.0065 & 0.0385 & 0.0012 & LSTR1 \\
Washington & $\mathrm{o}(\mathrm{t})$ & 0.0078 & 0.9035 & 0.0247 & 0.0046 & LSTR1 \\
Wyoming & $\mathrm{o}(\mathrm{t}-7)$ & 0.0006 & 0.0072 & 0.0178 & 0.1214 & LSTR1 \\
\hline \hline
\end{tabular}

Note: $p$-values are reported for the null hypothesis of no nonlinearity. These thirteen states failed to reject the $F$-test for nonlinearity in step one, indicating the presence of a nonlinear model. All other states failed the test.

\footnotetext{
${ }^{8}$ More detailed estimation results of the 13 models are provided in Table A2 of the Appendix.
} 
Table 2: Estimates of Models for State Earnings

\begin{tabular}{|c|c|c|c|c|}
\hline State & $\begin{array}{c}\text { Transition } \\
\text { Variable }\end{array}$ & $\gamma$ & $c$ & $c 2$ \\
\hline Alabama & $\mathrm{o}(\mathrm{t}-8)$ & $5.08 *$ & $-0.0614 * * *$ & \\
\hline Arkansas & $\mathrm{o}(\mathrm{t}-8)$ & $4.52 *$ & $0.0982 * * *$ & \\
\hline Georgia & $\mathrm{o}(\mathrm{t}-8)$ & $11.15 * *$ & $-0.1336 * * *$ & $-0.041 * * *$ \\
\hline Maryland & $\mathrm{o}(\mathrm{t}-8)$ & $14.46^{*}$ & $-0.0456 * * *$ & \\
\hline Minnesota & $\mathrm{o}(\mathrm{t}-8)$ & $0.78 *$ & $-0.0970 * * *$ & $0.169 * * *$ \\
\hline Missouri & $\mathrm{o}(\mathrm{t}-8)$ & $6.53 *$ & $-0.0709 * * *$ & \\
\hline New York & $\mathrm{o}(\mathrm{t}-8)$ & $60.38^{*}$ & $-0.0699 * * *$ & \\
\hline North Carolina & $\mathrm{o}(\mathrm{t}-4)$ & $6.56^{* *}$ & $0.0426^{* * *}$ & \\
\hline Oklahoma & $o(t-3)$ & $4.06 * *$ & $0.0335 * * *$ & \\
\hline Texas & $\mathrm{o}(\mathrm{t})$ & $10.96^{*}$ & $-0.0431 * * *$ & $0.017 * * *$ \\
\hline Virginia & $\mathrm{o}(\mathrm{t}-8)$ & $3.49 * * *$ & $-0.0702 * * *$ & \\
\hline Washington & $\mathrm{o}(\mathrm{t})$ & $4.236^{*}$ & $-0.0501 * * *$ & \\
\hline Wyoming & $\mathrm{o}(\mathrm{t}-7)$ & $8.58 *$ & $-0.0138 * *$ & \\
\hline
\end{tabular}

\section{Figure 1: Cross-Plot of Transition Function $(G)$ against Transition Variable (typical} regime: $G=0$ )

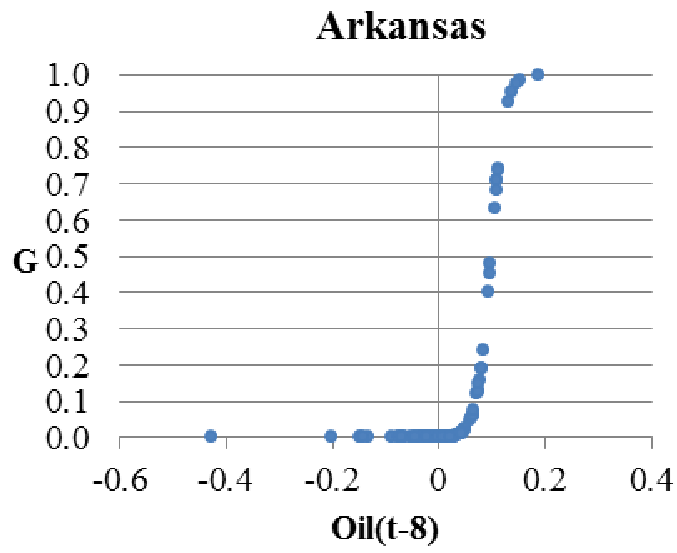

(C) Southern Regional Science Association 2012. 
Figure 2: Cross-Plot of Transition Function $(G)$ against Transition Variable (typical regime: $G=1$ )
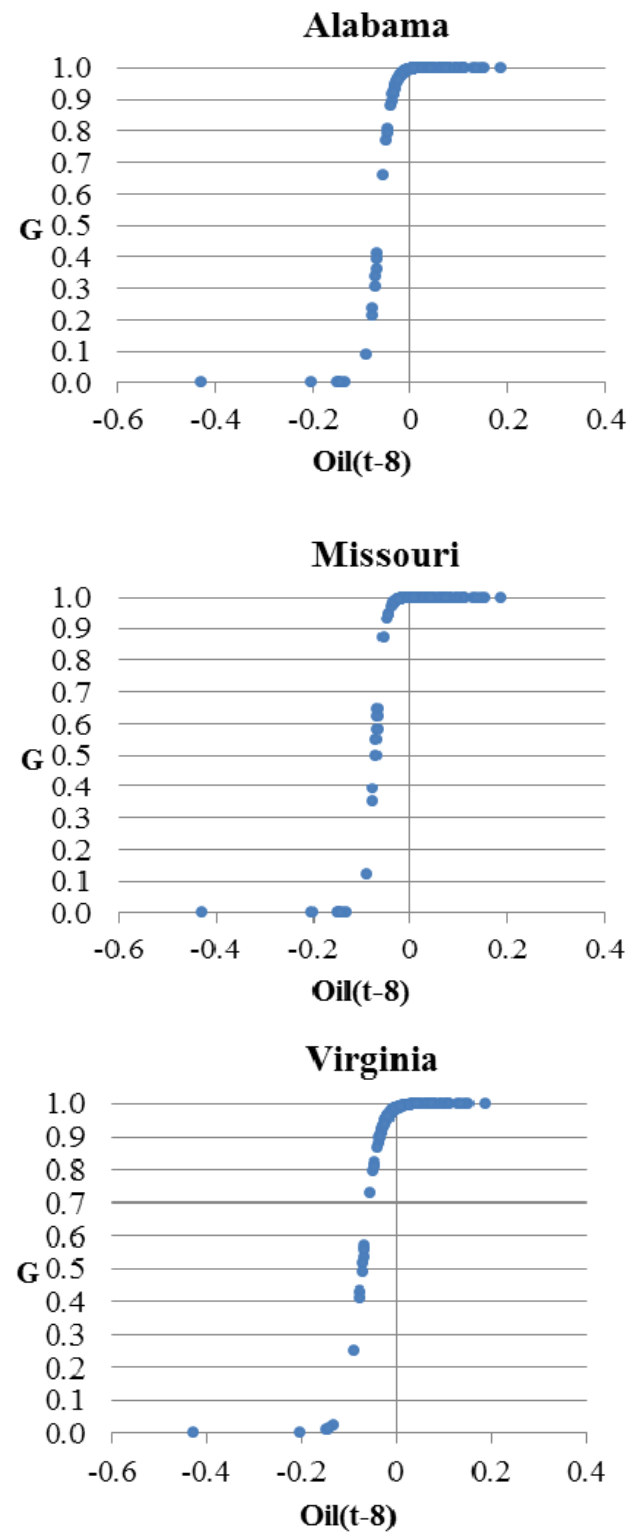
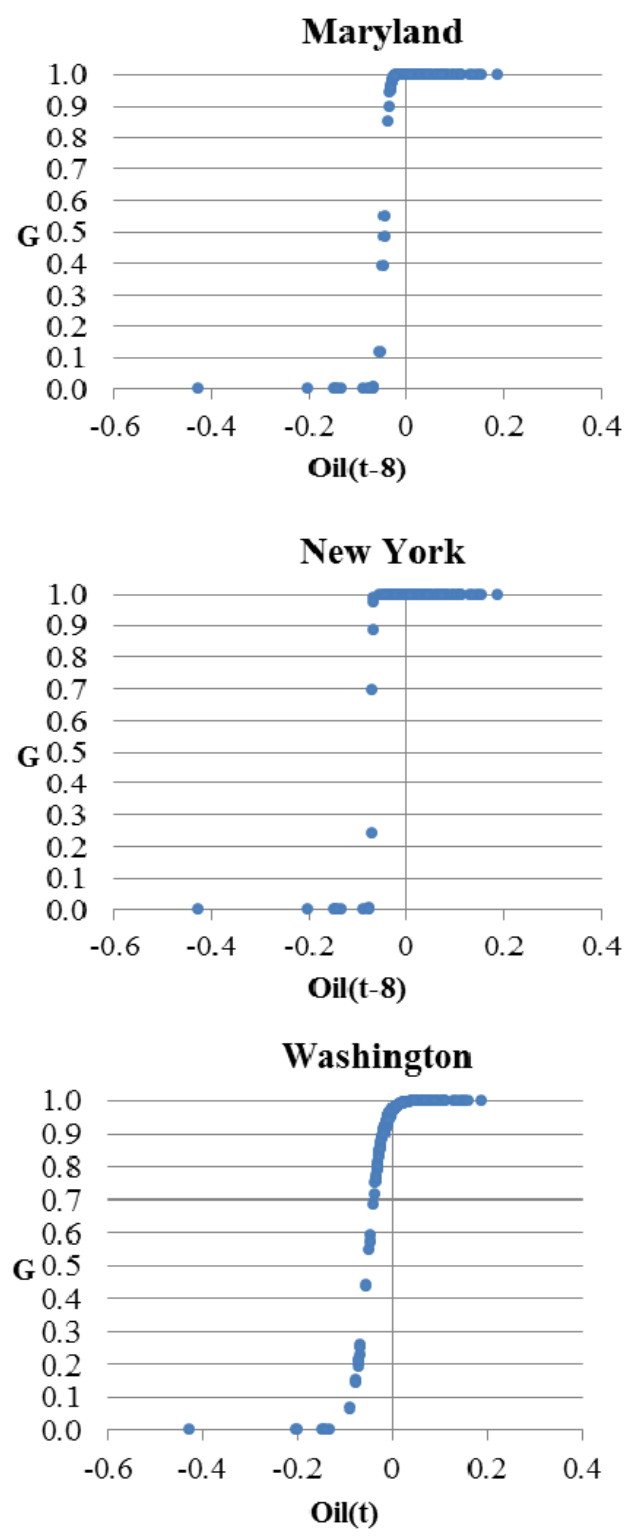

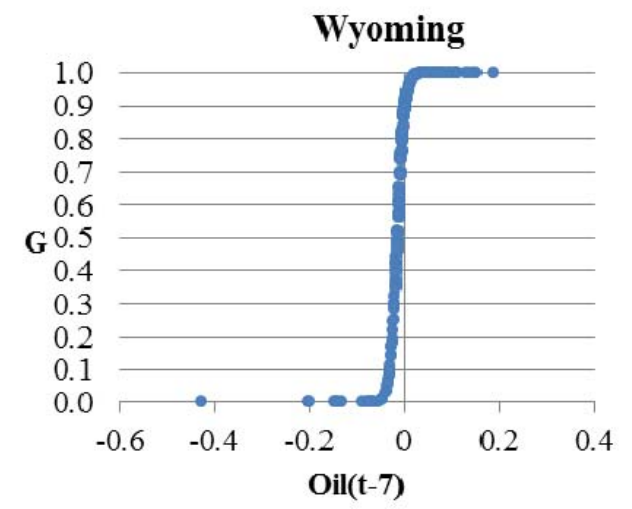

(C) Southern Regional Science Association 2012. 
Figure 3: Cross-Plot of Transition Function (G) against Transition Variable (typical regime: unclear)
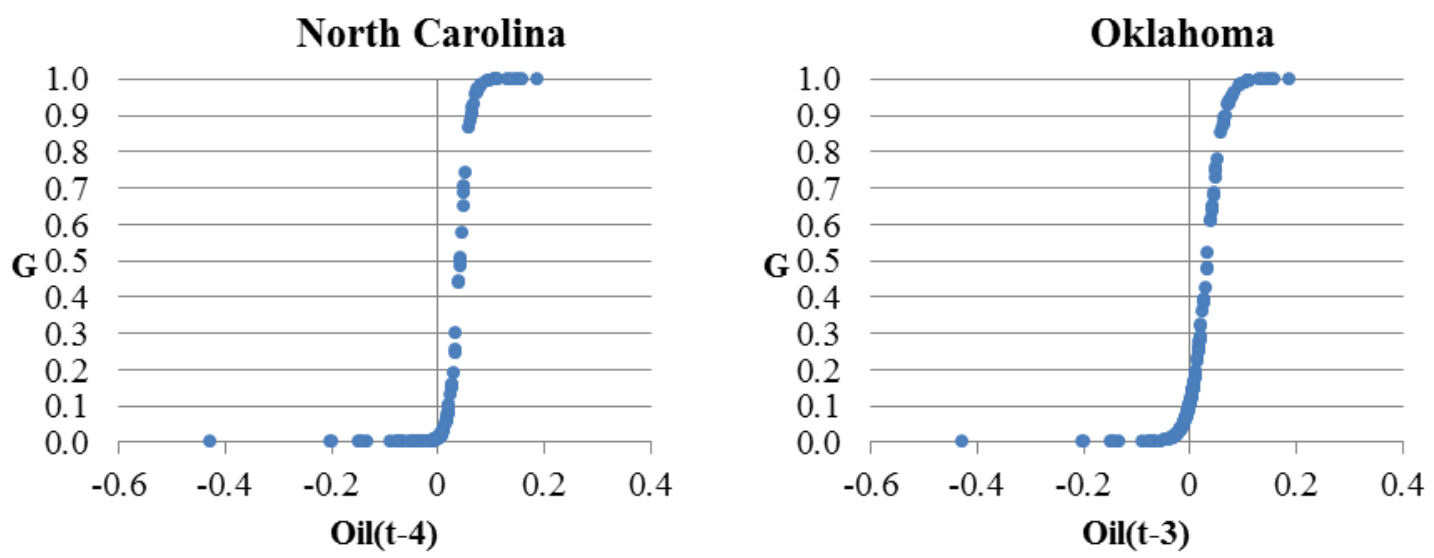

Figure 4: Cross-Plot of Transition Function (G) against Transition Variable (LSTR2 models)
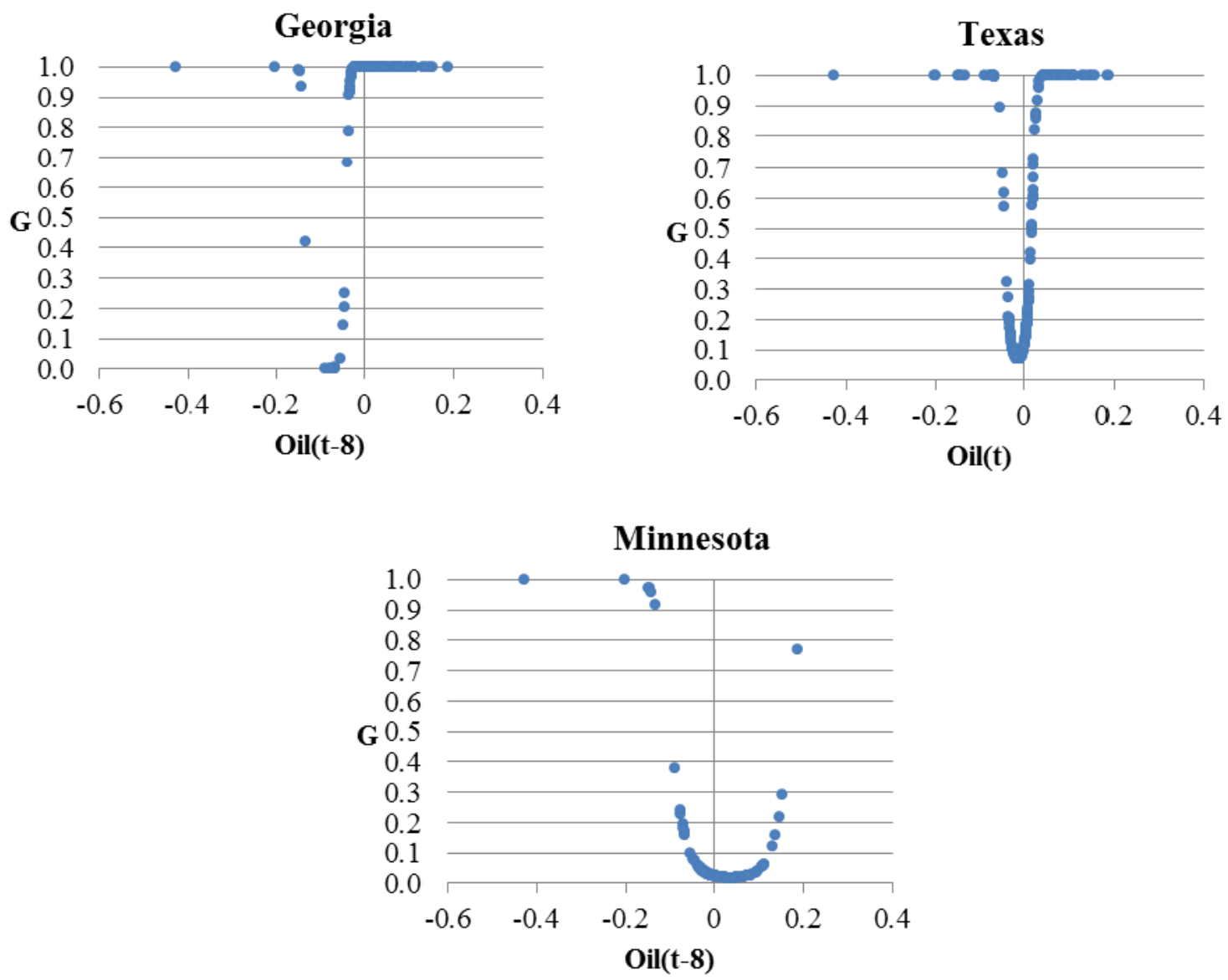

(C) Southern Regional Science Association 2012. 
Figure 3 captures two states, North Carolina and Oklahoma, for which neither regime is more likely than the other. Most of the oil price changes occur between regimes for these states. The critical value $c$ is in a range that the oil price change frequently crosses in one direction or the other as it changes over time.

Lastly, Figure 4 shows results for Georgia, Minnesota, and Texas, states that fit the LSTR2 model. For Georgia, the nonlinear regime $(G=1)$ is mostly relevant when the oil price change is larger than the upper critical value of $c 2=-0.041$. Only a few observations are in the nonlinear regime when the oil price change is below the lower threshold level of $c=-0.1336$. For Texas, the nonlinear regime, $G=1$, applies whenever the oil price change is below $c=-0.0431$ and above $\mathrm{c} 2=0.017$. As the two critical values of the oil price change are very close together for Texas, the adjustment paths between the regimes are also very close together in Figure 4 . It is also apparent that Texas is never in a strictly linear regime because the adjustment curve never touches the $G=0$ line; much of the time Texas is between regimes $G=0$ and $G=1$. For Minnesota things are different: the linear regime is in play over a wide range of oil price changes: from a low of -0.097 to a high of 0.169 .

The slope of the curves depicted in Figures 1 through 4 reflects the speed of adjustment between regimes, captured by the parameter $\gamma{ }^{9}$ Steeper curves reflect faster adjustment. When $\gamma$ is very large, such as for New York, the LSTR1 model approaches an instantaneous-transition model, in which the switch between regimes happens very quickly. By contrast, the transitions for Oklahoma, Virginia, and Washington are much more gradual; $\gamma$ for these three states is very small, less than 4.5. Differences in the adjustment paths are also clearly visible in Figure 4, which depicts the three cases with two threshold levels for the oil price change. The adjustment paths between regimes are significantly less steep for Minnesota than for Georgia and Texas. This reflects the low adjustment parameter for Minnesota, $\gamma<1$, and the large values of $\gamma$, around 11 , for Georgia and Texas.

The critical value $c$, the rate of oil price growth that marks the transition, is a key determinant of Figures 1 through 4. It is provided in Table 3. Economically, the parameter $c$ may be interpreted as the tolerance a state has for an increase in the price of oil. Arkansas has the highest positive oil price growth threshold (0.0982) among states that are negatively affected by rising oil prices, indicating that Arkansas's economy has a higher tolerance for negative oil price shocks than other state economies. By contrast, Virginia's threshold is very low at -0.0702 ; a price change greater than the threshold will generate a larger negative impact on the state's economy.

Table 3 provides a comparison between the estimated oil price effects from an OLS model and the STAR models. ${ }^{10}$ The STAR coefficients for the typical regime tend to be larger in magnitude than the OLS figures. In four states (Alabama, Georgia, Virginia, Wyoming), the OLS estimate is close to the STAR estimate for the typical regime. For other states, the OLS models will greatly under-estimate the impact of oil prices when they rise higher than the threshold. In Maryland, for example, the OLS model predicts only a very small negative impact

\footnotetext{
${ }^{9}$ Values for $\gamma$ are presented in Table 2.

${ }^{10}$ The estimates of the impact of oil prices from the threshold models in Table 3 are the sums of the oil price coefficients, excluding the insignificant ones. When $G=0$, the estimate is the sum of the coefficients in the linear part of the model; when $G=1$, the estimate is the sum of the coefficients from both the linear and nonlinear parts of the model. Table A1 presents more detailed estimation of the coefficients of the LSTR1 models. The OLS model parameters are selected using the System Sequential Elimination of Regressors (SER) routine implemented in JMULTI.
}

(C) Southern Regional Science Association 2012. 
$(-0.007)$ on the rate of growth of private earnings. However, the STAR model tells us that Maryland earnings growth will experience a large negative impact (-0.0993) when oil price growth rises above the threshold. The OLS model fails to take into account the important threshold effect.

To illustrate the interpretation of the response of private earnings to oil price changes, we consider the state of Wyoming, which has consistently positive oil price coefficients and a low threshold value $(-0.0138)$ according to Table 3 . For this state, we calculate a response of the growth rate of private earnings to a change in the oil price growth rate of 0.188 if the oil price increase is above the threshold value of -0.0138 , and of 0.1144 if the growth rate of the oil price is below the threshold value. We note that the response parameter predicted by OLS is somewhere in between these two values. The response parameter of 0.188 has to be interpreted as follows. Assuming a realistic 10 percentage-point increase in the percentage change (growth rate) of the oil price, say from 0 percent to 10 percent, the percentage change (growth rate) of private earnings in the state is predicted to go up by 0.0188 , that is by close to 2 percentage points, say from 4 percent to 6 percent (Table 3). This result illustrates, not surprisingly, that oil price changes do matter a great deal for the state of Wyoming.

In addition to the threshold effect, the STAR models provide a better fit to the data. Table 4 shows fit statistics (adjusted R-squared) by state for both OLS and STAR models. For all but one state, the STAR models show a better fit, averaging 10.7 points higher than the OLS models.

The set of states fitting the nonlinear model are rather diverse. Some are well-established energy producing states (Texas, Oklahoma, Wyoming), while others are large energy consumers (Georgia, New York, Virginia, and Washington). Texas is both a large energy producer and consumer.

Table 3: Impact of Oil Prices on State Earnings

\begin{tabular}{lcccccc}
\hline \hline State & OLS & $G=0$ & $G=1$ & Typical & $c$ & $c 2$ \\
Alabama & -0.0380 & 0.0590 & -0.0319 & $G=1$ & -0.0614 & \\
Arkansas & -0.0900 & -0.0913 & -0.4945 & $G=0$ & 0.0982 & \\
Georgia* & -0.0370 & 0.2491 & -0.0337 & $G=1$ & $-0.1336 * * *$ & $-0.041^{* * *}$ \\
Maryland & -0.0070 & 0.2330 & -0.0993 & $G=1$ & -0.0456 & \\
Minnesota* & 0.0000 & -0.0420 & 0.3055 & $G=0$ & $-0.0970 * * *$ & $0.169 * * *$ \\
Missouri & -0.0850 & -0.2035 & -0.0710 & $G=1$ & -0.0709 & \\
New York & 0.0180 & -0.0843 & 0.0022 & $G=1$ & -0.0699 & \\
North Carolina & -0.0290 & -0.0742 & -0.1814 & Unclear & 0.0426 & \\
Oklahoma & 0.1750 & 0.1918 & 0.1748 & Unclear & 0.0335 & \\
Texas* & 0.0670 & 0.0000 & 0.1028 & $G=1$ & $-0.0431 * * *$ & $0.0171^{* * *}$ \\
Virginia & -0.0380 & -0.1776 & -0.0386 & $G=1$ & -0.0702 & \\
Washington & 0.0390 & 0.0000 & -0.0707 & $G=1$ & -0.0501 & \\
Wyoming & 0.1500 & 0.1144 & 0.1877 & $G=1$ & -0.0138 & \\
\hline \hline
\end{tabular}

*These states have two thresholds. The figures for $G=0$ and $G=1$ are the sums of the oil price coefficients that are significantly different from zero. 
Table 4: Fit for OLS and STAR Models (adjusted $R^{2}$ )

\begin{tabular}{lcc}
\hline \hline State & OLS & STAR \\
\hline Alabama & .3705 & .2534 \\
Arkansas & .2845 & .3266 \\
Georgia & .4816 & .6155 \\
Maryland & .2403 & .4129 \\
Minnesota & .2824 & .4846 \\
Missouri & .3341 & .4444 \\
New York & .2771 & .4268 \\
North Carolina & .3824 & .5443 \\
Oklahoma & .3797 & .5374 \\
Texas & .3464 & .4494 \\
Virginia & .2939 & .4291 \\
Washington & .2427 & .2559 \\
Wyoming & .4098 & .5306 \\
\hline \hline
\end{tabular}

While it is difficult to generalize about oil price effects, it is possible to explain the numbers for a given state. Take Texas, for example. A 10 percentage-point increase in oil prices will have a negligible effect on earnings growth until the threshold (-0.043) is reached. Beyond the threshold, a 10 percentage-point oil price increase will raise the growth rate of real earnings in Texas by about 1 percentage point, say from 2 to 3 percent. While the oil and gas industry has become relatively less important for Texas over the decades, a large oil price increase still exerts a positive and rather significant impact on earnings growth. For Oklahoma, another resourcebased state, the impact of an oil price hike on earnings growth is even more pronounced than for Texas. According to Table 3, Oklahoma earnings will experience a rise in their growth rate by about 2 percentage points when oil price growth is below the threshold and by 1.75 percentage points if oil price growth is above the threshold.

For four states, Arkansas, Missouri, North Carolina, and Virginia, the oil price impact is negative in both regimes. The interpretation of an oil price change is complicated by the fact that Arkansas and North Carolina have positive thresholds, while Missouri and Virginia thresholds are negative. For example, the negative impact on Arkansas becomes much more negative in the nonlinear regime, but only after oil prices rise greatly, more than 9.82 percent. North Carolina is more sensitive, with the greater negative impacts in the nonlinear regime taking place after oil prices rise by just 4.26 percent.

Finally, four states (Alabama, Georgia, Maryland, and Washington) have positive oil price coefficients in the linear regime and negative coefficients in the nonlinear regime. All four states have negative oil price thresholds. This means that an oil price decline below the threshold will boost earnings, but an oil price change above the threshold will have a negative effect on earned income.

Based on the figures and Tables 1,2, and 3, the dynamic behavior of an oil price shock on a state can be divided into regimes, where the regimes are tied to the oil price growth rate. 
Table 5: Predicting Nonlinearity of the Oil Price Response by a Logit Model

\begin{tabular}{lrrrr}
\hline \hline & & Standard & Wald Chi- & \\
Variable & Estimate & Error & Square & Pr>ChiSq \\
\hline Constant & 5.294 & 2.805 & 3.563 & 0.059 \\
Nondurables & -37.320 & 18.528 & 4.057 & 0.044 \\
Industrial & 12.419 & 4.892 & 6.445 & 0.011 \\
Fossil fuel & -30.237 & 15.341 & 3.885 & 0.049 \\
Commercial & -84.914 & 45.335 & 3.508 & 0.061 \\
$\begin{array}{l}\text { p-values for global tests : } \\
\text { Likelihood ratio }\end{array}$ & 0.010 & & & \\
$\quad$ Wald & 0.097 & & & \\
\hline \hline
\end{tabular}

Note: The dependent variable is 1 for a state with a nonlinear response and 0 for a state with a linear response to an oil price change. Thirteen states have a nonlinear response. Nondurables is the share of the state's GDP in nondurable manufacturing; Industrial is the share of the state's energy consumption by the industrial sector; Fossil fuel is the state's share of U.S. fossil fuel production; Commercial is energy consumption in the commercial sector per thousand population. Data are obtained from the Bureau of Economic Analysis (BEA) and the Energy Information Administration (EIA).

The fact that states move between regimes means that there is a nonlinear relationship between oil price changes and a state's economic activity. The estimated delay parameters $d$ are different across states, suggesting that state economies exhibit differences in the speed of response to an oil price shock. State economies with higher dependence on oil production tend to respond more quickly. States also differ in the speed of adjustment between regimes, which is indicated by the slope variable $\gamma$. Values of the transition variable $c$ are also different across states. This can be interpreted to mean that states have different degrees of tolerance to oil price shocks.

A remaining question is why do some states respond in a nonlinear fashion to oil price changes and others do not? Although an in-depth explanation is beyond the scope of this paper, our tentative results suggest that the probability of a nonlinear response has to do with energy consumption patterns. To illustrate, the results of a logit regression predicting a nonlinear response to oil price changes (Table 5) show that a nonlinear response is positively related to the industrial share of the state's energy consumption and negatively to (i) the share of nondurable manufacturing in a state's GDP, (ii) the state's share of U.S. fossil fuel production, and (iii) the state's commercial energy usage per thousand population. These results suggest that states with a strong presence in durable goods manufacturing, a relatively low share of U.S. fossil fuel production, and low commercial energy usage relative to the state's population are more likely to be in the nonlinear group. Clearly, more work is needed on this issue, as this result does not explain nonlinearity for Oklahoma, Texas, and Wyoming.

\section{CONCLUSION}

The notion that oil prices have an asymmetric effect on economic activity is well established for the U.S. and other nations. Extending this notion, we examine whether a similar nonlinear relationship exists at the state level, utilizing smooth transition autoregressive (STAR) models proposed by Teräsvirta (2004). The results show that a nonlinear relationship can be confirmed for thirteen states. 
The 13 states fitting the STAR model are a mix of oil-producing states and oil-consuming states. The estimation results show differences among states in both the tolerance and delay of response to an oil price shock. The delay of response is likely due to a state's dependence on oil, either in production or consumption, with these states tending to respond faster than others. States also differ in their tolerance to an oil price shock, which is indicated by the different critical threshold values of the transition variable. Arkansas and North Carolina experience the largest declines in earned income when oil price growth rises above the state's threshold value. The energy producing/energy processing states of Oklahoma, Texas, and Wyoming show positive impacts on earnings above the oil price threshold.

This study offers insights into the estimation of the nonlinear relationship between oil prices and the state-level economy, but also raises questions for future research. First, why does the linearity test suggest nonlinear models for some states and not others? Also, what might explain the varying threshold levels? Preliminary evidence suggests that the nonlinear model tends to fit states that consume relatively large shares of energy in the industrial sector and produce large shares of GDP in nondurable manufacturing. Variation in the threshold levels may also be due to energy consumption patterns. Clearly, more work is needed along these lines.

\section{REFERENCES}

Amisano, Gianni and Gabriel Fagan. (2010) "Money Growth and Inflation: A Regime Switching Approach," European Central Bank Working Paper No. 1207, last accessed May 2012 at https://www.ecb.europa.eu/pub/pdf/scpwps/ecbwp1207.pdf.

Chan, K. S. (1993) "Consistency and Limiting Distribution of the Least Squares Estimator of a Threshold Autoregressive Model," Annals of Statistics, 21, 520-533.

Cuñado, Juncal and Fernando Pérez de Gracia. (2003) "Do Oil Price Shocks Matter? Evidence from Some European Countries," Energy Economics, 25, 137-154.

van Dijk, Dick, Timo Teräsvirta, and Philip H. Franses. (2002) "Smooth Transition Autoregressive Models-A Survey of Recent Developments," Econometrics Reviews, 21, $1-47$.

Enders, Walter. (2004) Applied Econometric Time Series, $2^{\text {nd }}$ ed. John Wiley \& Sons: Hoboken, N.J.

Franses, Philip H. and Dick van Dijk. (2000) Non-linear Time Series Models in Empirical Finance. Cambridge University Press: Cambridge, U.K.

Füss, Roland, Michael Stein, and Joachim Zietz. (2012) "A Regime-Switching Approach to Modeling Rental Prices of UK Real Estate Sectors," Real Estate Economics, 40, 317350 .

Hamilton, James D. (1983) "Oil and the Macroeconomy since World War II," Journal of Political Economy, 91, 228-248. . (2003) “What Is an Oil Shock?” Journal of Econometrics, 113, 363-398.

Huang, Bow-Nung. (2008) "Factors Affecting an Economy's Tolerance and Delay of Response to the Impact of a Positive Oil Price Shock," Energy Journal, 29, 35-52.

(C) Southern Regional Science Association 2012. 
Kilian, Lutz. (2008) "The Economic Effects of Energy Price Shocks," Journal of Economic Literature, 46, 871-909.

Lee, Kiseok, Shawn Ni, and Ronald A. Ratti. (1995) "Oil Shocks and the Macroeconomy: The Role of Price Variability," Energy Journal, 16, 39-56.

Liu, Dandan, Dennis Jansen, and Qi Li. (2005) "Regime Switching in the Dynamic Relationship Between Stock Returns and Inflation," Applied Economics Letters, 1, 273-277.

Luukkonen, Ritva, Pentti Saikkonen, and Timo Teräsvirta. (1988) "Testing Linearity against Smooth Transition Autoregressive Models," Biometrika, 75, 491-499.

Mork, Knut A. (1989) "Oil and the Macroeconomy, When Prices Go Up and Down: An Extension of Hamilton's Results," Journal of Political Economy, 97, 740-744.

Penn, David A. (2006) "What Do We Know about Oil Prices and State Economic Performance?" Regional Economic Development, Federal Reserve Bank of St. Louis, 2, 131-139.

Renkl, Alexander, Robert K. Atkinson, Uwe H. Maier, and Richard Staley. (2002) "From Example Study to Problem Solving: Smooth Transitions Help Learning," Journal of Experimental Education, 70, 293-315.

Teräsvirta, Timo. (1994) "Specification, Estimation, and Evaluation of Smooth Transition Autoregressive Models," Journal of the American Statistical Association, 89, 208-218.

. (2004) "Smooth Transition Regression Modeling," in Helmut Lütkepohl and Markus Krätzig (eds.), Applied Time Series Econometrics. Cambridge University Press: Cambridge, U.K., pp. 222-242

Teräsvirta, Timo and Heather M. Anderson. (1992) "Characterizing Nonlinearities in Business Cycles Using Smooth Transition Autoregressive Models," Journal of Applied Econometrics, 7, S119-135.

Tsay, Ruey S. (1989) “Testing and Modeling Threshold Autoregressive Processes," Journal of the American Statistical Association, 84, 231-240.

(C) Southern Regional Science Association 2012. 


\section{APPENDIX \\ Table A1: Quarterly Growth Rates in State Earnings and in other Variables, 1958:I - 2010:IV}

\begin{tabular}{|c|c|c|c|c|c|c|}
\hline Variable & Definition & Mean & Median & $\operatorname{Max}$ & Min & Std. \\
\hline $\mathrm{AL}$ & $\begin{array}{l}\text { State Earnings in: } \\
\text { Alabama }\end{array}$ & 0.0073 & 0.0084 & 0.0484 & -0.0315 & 0.0135 \\
\hline $\mathrm{AK}$ & Alaska & 0.0117 & 0.0054 & 0.2134 & -0.1567 & 0.0379 \\
\hline $\mathrm{AZ}$ & Arizona & 0.0127 & 0.0151 & 0.0547 & -0.0396 & 0.0169 \\
\hline AR & Arkansas & 0.0087 & 0.0091 & 0.0512 & -0.0449 & 0.0143 \\
\hline $\mathrm{CA}$ & California & 0.0087 & 0.0099 & 0.0485 & -0.0420 & 0.0128 \\
\hline $\mathrm{CO}$ & Colorado & 0.0107 & 0.0112 & 0.0520 & -0.0343 & 0.0151 \\
\hline $\mathrm{CT}$ & Connecticut & 0.0066 & 0.0072 & 0.0513 & -0.0386 & 0.0140 \\
\hline $\mathrm{DE}$ & Delaware & 0.0074 & 0.0079 & 0.0717 & -0.0668 & 0.0181 \\
\hline FL & Florida & 0.0115 & 0.0130 & 0.0637 & -0.0453 & 0.0147 \\
\hline GA & Georgia & 0.0102 & 0.0106 & 0.0424 & -0.0387 & 0.0134 \\
\hline HI & Hawaii & 0.0100 & 0.0103 & 0.0673 & -0.0306 & 0.0151 \\
\hline ID & Idaho & 0.0089 & 0.0089 & 0.0711 & -0.0436 & 0.0170 \\
\hline IL & Illinois & 0.0051 & 0.0066 & 0.0385 & -0.0492 & 0.0130 \\
\hline IN & Indiana & 0.0052 & 0.0068 & 0.0588 & -0.0514 & 0.0174 \\
\hline IA & Iowa & 0.0060 & 0.0061 & 0.0381 & -0.0385 & 0.0129 \\
\hline KS & Kansas & 0.0066 & 0.0075 & 0.0551 & -0.0450 & 0.0133 \\
\hline KY & Kentucky & 0.0070 & 0.0073 & 0.0858 & -0.0435 & 0.0157 \\
\hline LA & Louisiana & 0.0070 & 0.0078 & 0.0613 & -0.0384 & 0.0144 \\
\hline ME & Maine & 0.0067 & 0.0065 & 0.0774 & -0.0372 & 0.0154 \\
\hline MD & Maryland & 0.0083 & 0.0101 & 0.0371 & -0.0623 & 0.0129 \\
\hline MA & Massachusetts & 0.0071 & 0.0071 & 0.0512 & -0.0548 & 0.0139 \\
\hline MI & Michigan & 0.0043 & 0.0048 & 0.0748 & -0.0737 & 0.0234 \\
\hline $\mathrm{MN}$ & Minnesota & 0.0081 & 0.0089 & 0.0460 & -0.0404 & 0.0135 \\
\hline MS & Mississippi & 0.0079 & 0.0074 & 0.0647 & -0.0482 & 0.0135 \\
\hline MO & Missouri & 0.0061 & 0.0069 & 0.0555 & -0.0663 & 0.0129 \\
\hline MT & Montana & 0.0063 & 0.0065 & 0.0672 & -0.0514 & 0.0165 \\
\hline $\mathrm{NE}$ & Nebraska & 0.0072 & 0.0073 & 0.0536 & -0.0288 & 0.0121 \\
\hline NV & Nevada & 0.0141 & 0.0149 & 0.1047 & -0.0480 & 0.0208 \\
\hline NH & New Hampshire & 0.0093 & 0.0106 & 0.0548 & -0.0469 & 0.0175 \\
\hline NJ & New Jersey & 0.0065 & 0.0071 & 0.0340 & -0.0475 & 0.0132 \\
\hline NM & New Mexico & 0.0084 & 0.0098 & 0.0593 & -0.0380 & 0.0133 \\
\hline NY & New York & 0.0054 & 0.0062 & 0.0659 & -0.0856 & 0.0182 \\
\hline $\mathrm{NC}$ & North Carolina & 0.0094 & 0.0113 & 0.0622 & -0.0562 & 0.0147 \\
\hline ND & North Dakota & 0.0080 & 0.0069 & 0.0989 & -0.0303 & 0.0161 \\
\hline $\mathrm{OH}$ & Ohio & 0.0044 & 0.0055 & 0.0428 & -0.0595 & 0.0155 \\
\hline OK & Oklahoma & 0.0075 & 0.0097 & 0.0694 & -0.0823 & 0.0167 \\
\hline OR & Oregon & 0.0080 & 0.0085 & 0.0514 & -0.0413 & 0.0155 \\
\hline PA & Pennsylvania & 0.0048 & 0.0057 & 0.0495 & -0.0443 & 0.0130 \\
\hline RI & Rhode Island & 0.0057 & 0.0070 & 0.0438 & -0.0455 & 0.0152 \\
\hline $\mathrm{SC}$ & South Carolina & 0.0090 & 0.0103 & 0.0499 & -0.0639 & 0.0149 \\
\hline SD & South Dakota & 0.0080 & 0.0067 & 0.0743 & -0.0503 & 0.0156 \\
\hline $\mathrm{TN}$ & Tennessee & 0.0087 & 0.0101 & 0.0434 & -0.0289 & 0.0131 \\
\hline $\mathrm{TX}$ & Texas & 0.0103 & 0.0118 & 0.0438 & -0.0625 & 0.0132 \\
\hline UT & Utah & 0.0104 & 0.0099 & 0.0491 & -0.0261 & 0.0143 \\
\hline VT & Vermont & 0.0078 & 0.0084 & 0.0426 & -0.0462 & 0.0155 \\
\hline VA & Virginia & 0.0101 & 0.0104 & 0.0464 & -0.0282 & 0.0128 \\
\hline WA & Washington & 0.0089 & 0.0081 & 0.0573 & -0.0473 & 0.0170 \\
\hline WV & West Virginia & 0.0034 & 0.0040 & 0.1837 & -0.1409 & 0.0286 \\
\hline WI & Wisconsin & 0.0063 & 0.0078 & 0.0359 & -0.0385 & 0.0128 \\
\hline WY & Wyoming & 0.0082 & 0.0100 & 0.0603 & -0.0739 & 0.0225 \\
\hline o & Growth rate of gasoline price & 0.0031 & 0.0004 & 0.1877 & -0.4266 & 0.0610 \\
\hline $\mathrm{r}$ & Change in federal funds rate & -0.0145 & 0.0083 & 6.0167 & -3.9900 & 0.9508 \\
\hline $\mathrm{s}$ & Growth rate of S\&P 500 & 0.0063 & 0.0095 & 0.1802 & -0.2953 & 0.0641 \\
\hline
\end{tabular}

(C) Southern Regional Science Association 2012. 
Table A2: Estimates of Models for State Incomes (Part I:A)

\begin{tabular}{|c|c|c|c|c|c|c|c|}
\hline State & Alabama & Arkansas & Georgia & Maryland & Minnesota & Missouri & $\begin{array}{r}\text { New } \\
\text { York }\end{array}$ \\
\hline Transition Variable & $\mathrm{o}(\mathrm{t}-8)$ & $o(t-8)$ & $\mathrm{o}(\mathrm{t}-8)$ & $\mathrm{o}(\mathrm{t}-8)$ & $\mathrm{o}(\mathrm{t}-8)$ & $\mathrm{o}(\mathrm{t}-8)$ & $\mathrm{o}(\mathrm{t}-8)$ \\
\hline \multicolumn{8}{|c|}{ Linear Part } \\
\hline Constant & 0.009 & $0.006 * * *$ & 0.014 & 0.005 & 0.003 & -0.008 & $0.048 * * *$ \\
\hline$y(t-1)$ & & & $-1.177 * * *$ & & $-0.169 * *$ & & $1.596 * * *$ \\
\hline $\begin{array}{l}y(t-2) \\
y(t-3)\end{array}$ & & $0.159 * *$ & & $1.071 * *$ & & & $1.823 * * *$ \\
\hline $\begin{array}{l}\mathrm{y}(\mathrm{t}-4) \\
\mathrm{y}(\mathrm{t}-5) \\
\mathrm{y}(\mathrm{t}-6) \\
\mathrm{y}(\mathrm{t}-7) \\
\mathrm{y}(\mathrm{t}-8)\end{array}$ & $1.375^{* *}$ & $0.189 * * *$ & & & & & \\
\hline $\begin{array}{c}o(t) \\
o(t-1)\end{array}$ & $0.059 *$ & $-0.043 * * *$ & $0.249 * *$ & $-0.052 * * *$ & $-0.042 * *$ & $\begin{array}{l}-0.153 * * * \\
-0.462 * * *\end{array}$ & \\
\hline$o(t-2)$ & & & & $0.151 * *$ & & & \\
\hline$o(t-3)$ & & & & & & $0.434 * * *$ & \\
\hline$o(t-4)$ & & $-0.048 * * *$ & & & & $-0.023^{*}$ & \\
\hline \multicolumn{8}{|l|}{$\mathrm{o}(\mathrm{t}-5)$} \\
\hline$o(t-6)$ & & & & $0.134 *$ & & & \\
\hline$o(t-7)$ & & & & & & & $0.377 * * *$ \\
\hline $\mathrm{o}(\mathrm{t}-8)$ & & & & & & & $0.293 * * *$ \\
\hline \multicolumn{8}{|l|}{$\mathrm{r}(\mathrm{t}-1)$} \\
\hline $\mathrm{r}(\mathrm{t}-2)$ & & & $0.017^{*}$ & & $-0.002 * *$ & & \\
\hline$r(t-3)$ & & -0.002 & & & & & \\
\hline$r(t-4)$ & & & & $0.046 * * *$ & & & \\
\hline \multicolumn{8}{|l|}{$r(t-5)$} \\
\hline \multicolumn{8}{|l|}{$r(t-6)$} \\
\hline \multicolumn{8}{|l|}{$r(t-7)$} \\
\hline \multicolumn{8}{|l|}{$\mathrm{r}(\mathrm{t}-8)$} \\
\hline $\mathrm{s}(\mathrm{t})$ & & & $-0.653 * * *$ & & & & \\
\hline $\mathrm{s}(\mathrm{t}-1)$ & & & & $0.034 * * *$ & $0.061 * *$ & $0.041 * * *$ & $0.102 * * *$ \\
\hline $\mathrm{s}(\mathrm{t}-2)$ & & & & $0.047 * * *$ & $0.047 * * *$ & & \\
\hline$s(t-3)$ & & $0.034 * *$ & $0.028 * *$ & & $0.047 * * *$ & & \\
\hline $\mathrm{s}(\mathrm{t}-4)$ & & & & & & $0.279 * * *$ & \\
\hline \multicolumn{8}{|l|}{$\mathrm{s}(\mathrm{t}-5)$} \\
\hline \multicolumn{8}{|l|}{$s(t-6)$} \\
\hline $\mathrm{s}(\mathrm{t}-7)$ & & & $-0.208 * *$ & & $-0.033 * * *$ & & \\
\hline \multicolumn{8}{|l|}{$\mathrm{s}(\mathrm{t}-8)$} \\
\hline \multicolumn{8}{|l|}{ spatial } \\
\hline spatial(t-1) & $-1.16 * * *$ & & & & & $-1.142 * * *$ & $-2.333 * *$ \\
\hline spatial(t-2) & & & $-0.956^{*}$ & & $0.242 *$ & & $5.297 * * *$ \\
\hline spatial(t-3) & & & -0.527 & & $0.47 * *$ & -0.094 & \\
\hline spatial(t-4) & & & $0.159 * *$ & $-1.009 * *$ & $0.242 * * *$ & & \\
\hline spatial(t-5) & & & $3.213 * *$ & & & & \\
\hline \multicolumn{8}{|l|}{ spatial(t-6) } \\
\hline \multicolumn{8}{|l|}{ spatial(t-7) } \\
\hline spatial(t-8) & & & & & & & \\
\hline
\end{tabular}

(C) Southern Regional Science Association 2012. 
Table A2: Estimates of Models for State Incomes (Part I:B)

\begin{tabular}{|c|c|c|c|c|c|c|c|}
\hline State & Alabama & Arkansas & Georgia & Maryland & Minnesota & Missouri & New York \\
\hline $\begin{array}{c}\text { Transition } \\
\text { Variable }\end{array}$ & $\mathrm{o}(\mathrm{t}-8)$ & $\mathrm{o}(\mathrm{t}-8)$ & $\mathrm{o}(\mathrm{t}-8)$ & $\mathrm{o}(\mathrm{t}-8)$ & $\mathrm{o}(\mathrm{t}-8)$ & $\mathrm{o}(\mathrm{t}-8)$ & $\mathrm{o}(\mathrm{t}-8)$ \\
\hline \multicolumn{8}{|c|}{ Nonlinear Part } \\
\hline Constant & -0.005 & -0.006 & -0.011 & 0.001 & $0.060^{* * *}$ & 0.011 & $-0.046^{* * *}$ \\
\hline $\mathrm{y}(\mathrm{t}-1)$ & & $0.806^{*}$ & $1.497 * * *$ & & -0.397 & $-0.286^{* * *}$ & $1.166^{* * *}$ \\
\hline$y(t-2)$ & & $0.821 * *$ & & $-0.945^{* *}$ & & & $1.698 * * *$ \\
\hline$y(t-3)$ & & & & & & 0.161 & \\
\hline \multirow{2}{*}{\multicolumn{8}{|c|}{$y(t-5)$}} \\
\hline & & & & & & & \\
\hline \multicolumn{8}{|l|}{$y(t-6)$} \\
\hline \multicolumn{8}{|l|}{$y(t-7)$} \\
\hline \multicolumn{8}{|l|}{$y(t-8)$} \\
\hline$o(t)$ & $-0.091 * *$ & & $-0.283 * * *$ & & $0.347 * * *$ & $0.107 * *$ & \\
\hline$o(t-1)$ & & & & & & $0.477 * * *$ & \\
\hline$o(t-2)$ & & & & $-0.175^{* *}$ & & & \\
\hline$o(t-3)$ & & & & & & $-0.452 * * *$ & \\
\hline \multicolumn{8}{|l|}{$o(t-4)$} \\
\hline \multicolumn{8}{|l|}{$o(t-5)$} \\
\hline$o(t-6)$ & & $-0.403 * * *$ & & $-0.158 * *$ & & & \\
\hline$o(t-7)$ & & & & & & & $0.347 * * *$ \\
\hline $\mathrm{o}(\mathrm{t}-8)$ & & & & & & & $-0.261 * * *$ \\
\hline \multicolumn{8}{|l|}{$r(t)$} \\
\hline \multicolumn{8}{|l|}{$\mathrm{r}(\mathrm{t}-1)$} \\
\hline $\mathrm{r}(\mathrm{t}-2)$ & & & $-0.02 * *$ & & & $-0.002 * *$ & \\
\hline$r(t-3)$ & & $0.007 *$ & & & & & \\
\hline $\mathrm{r}(\mathrm{t}-4)$ & & & & $-0.048 * * *$ & & & \\
\hline \multicolumn{8}{|l|}{$r(t-5)$} \\
\hline \multicolumn{8}{|l|}{$\mathrm{r}(\mathrm{t}-6)$} \\
\hline \multicolumn{8}{|l|}{$\mathrm{r}(\mathrm{t}-7)$} \\
\hline \multicolumn{8}{|l|}{$\mathrm{r}(\mathrm{t}-8)$} \\
\hline $\mathrm{s}(\mathrm{t})$ & & & $0.68^{* * *}$ & & & & \\
\hline $\mathrm{s}(\mathrm{t}-1)$ & $1.595 * * *$ & & $0.049 * * *$ & & $-0.617 * * *$ & & \\
\hline $\mathrm{s}(\mathrm{t}-2)$ & & & & & $-0.18 * *$ & & \\
\hline \multicolumn{8}{|l|}{$\mathrm{s}(\mathrm{t}-3)$} \\
\hline $\mathrm{s}(\mathrm{t}-4)$ & & & & & & $-0.253 * *$ & \\
\hline \multicolumn{8}{|l|}{$\mathrm{s}(\mathrm{t}-5)$} \\
\hline \multicolumn{8}{|l|}{$\mathrm{s}(\mathrm{t}-6)$} \\
\hline $\mathrm{s}(\mathrm{t}-7)$ & & & $0.192 * *$ & & & & \\
\hline \multicolumn{8}{|l|}{$\mathrm{s}(\mathrm{t}-8)$} \\
\hline \multicolumn{8}{|l|}{ spatial } \\
\hline spatial(t-1) & & & & & & $1.617 * * *$ & $2.827 * * *$ \\
\hline spatial(t-2) & & & $1.224^{* *}$ & & $-2.551^{*}$ & $0.271 * * *$ & $-4.899 * * *$ \\
\hline spatial(t-3) & & & $0.672 *$ & & $-4.19 * * *$ & & \\
\hline spatial(t-4) & & & & $1.278 * * *$ & & & \\
\hline spatial(t-5) & & & $-3.389 * *$ & & & & \\
\hline \multirow{3}{*}{\multicolumn{8}{|c|}{$\begin{array}{l}\text { spatial(t-6) } \\
\text { spatial(t-7) } \\
\text { spatial(t-8) }\end{array}$}} \\
\hline & & & & & & & \\
\hline & & & & & & & \\
\hline gamma & $5.08^{*}$ & $4.523^{*}$ & $11.153^{* *}$ & $14.464 *$ & $0.781^{*}$ & $6.528^{*}$ & $60.379 *$ \\
\hline$c$ & $-0.061 * * *$ & $0.098 * * *$ & $-0.134 * * *$ & $-0.046^{* * *}$ & $-0.097 * * *$ & $-0.071 * * *$ & $-0.07 * * *$ \\
\hline$c 2$ & & & $-0.41 * * *$ & & $0.169 * * *$ & & \\
\hline$R^{2}$ & 0.253 & 0.327 & 0.6155 & 0.4129 & 0.4846 & 0.4444 & 0.4268 \\
\hline AIC & -8.884 & -8.766 & -9.350 & -9.271 & -9.105 & -9.096 & -8.377 \\
\hline
\end{tabular}

Note: $* * *$ indicates $1 \%$ significance level; $* * 5 \%$ significance; $* 10 \%$ significance. 
Table A2: Estimates of Models for State Incomes (Part II:A)

\begin{tabular}{|c|c|c|c|c|c|c|}
\hline State & North Carolina & Oklahoma & Texas & Virginia & Washington & Wyoming \\
\hline $\begin{array}{c}\text { Transition } \\
\text { Variable } \\
\end{array}$ & $\mathrm{o}(\mathrm{t}-4)$ & $o(t-3)$ & $o(t)$ & $\mathrm{o}(\mathrm{t}-8)$ & $o(t)$ & $o(t-7)$ \\
\hline \multicolumn{7}{|c|}{ Linear Part } \\
\hline Constant & $0.006^{* * *}$ & $0.002 *$ & $0.008 * * *$ & 0.005 & 0.005 & $-0.008^{*}$ \\
\hline$y(t-1)$ & $-0.286^{* *}$ & & & & & $0.361 * * *$ \\
\hline$y(t-2)$ & & & $0.476^{* * *}$ & & & \\
\hline$y(t-3)$ & & 0.092 & & -0.212 & & \\
\hline$y(t-4)$ & & & & -0.256 & $1.444 * * *$ & \\
\hline$y(t-5)$ & $-0.303 * *$ & & & $2.250 * * *$ & & \\
\hline \multicolumn{7}{|l|}{$y(t-6)$} \\
\hline \multicolumn{7}{|l|}{$y(t-7)$} \\
\hline \multicolumn{7}{|l|}{$y(t-8)$} \\
\hline$o(t)$ & $-0.074 * * *$ & $0.034^{* *}$ & & $-0.178 * * *$ & & \\
\hline $\mathrm{o}(\mathrm{t}-1)$ & & & -0.032 & & & 0.032 \\
\hline$o(t-2)$ & & $0.111 * * *$ & & & & \\
\hline$o(t-3)$ & & & & & & $0.114 * *$ \\
\hline $\mathrm{o}(\mathrm{t}-4)$ & & $0.047 * * *$ & & & & \\
\hline \multicolumn{7}{|l|}{$o(t-5)$} \\
\hline \multicolumn{7}{|l|}{$o(t-6)$} \\
\hline \multicolumn{7}{|l|}{$o(t-7)$} \\
\hline \multicolumn{7}{|l|}{$\mathrm{o}(\mathrm{t}-8)$} \\
\hline$r(t)$ & $0.002 * *$ & & & & $0.018^{* *}$ & \\
\hline \multicolumn{7}{|l|}{$\mathrm{r}(\mathrm{t}-1)$} \\
\hline$r(t-2)$ & & & & $0.040^{* * *}$ & & \\
\hline$r(t-3)$ & $-0.002 * *$ & & & & & \\
\hline$r(t-4)$ & $-0.003 * * *$ & & & & & $-0.009 *$ \\
\hline$r(t-5)$ & $-0.002 * *$ & & & & & \\
\hline $\mathrm{r}(\mathrm{t}-6)$ & & & & & & $0.005^{* *}$ \\
\hline$r(t-7)$ & & $-0.003 * *$ & 0.001 & & & $-0.014 * *$ \\
\hline \multicolumn{7}{|l|}{$\mathrm{r}(\mathrm{t}-8)$} \\
\hline \multicolumn{7}{|l|}{$\mathrm{s}(\mathrm{t})$} \\
\hline $\mathrm{s}(\mathrm{t}-1)$ & $0.045^{* * *}$ & & & $0.172 * *$ & & $0.052 * * *$ \\
\hline \multicolumn{7}{|l|}{$\mathrm{s}(\mathrm{t}-2)$} \\
\hline \multicolumn{7}{|l|}{$\mathrm{s}(\mathrm{t}-3)$} \\
\hline $\mathrm{s}(\mathrm{t}-4)$ & & 0.019 & & & & \\
\hline \multicolumn{7}{|l|}{$s(t-5)$} \\
\hline$s(t-6)$ & & -0.017 & & & & \\
\hline$s(t-7)$ & & $-0.052 * * *$ & & $-0.370 * * *$ & & $-0.062 * * *$ \\
\hline $\mathrm{s}(\mathrm{t}-8)$ & $-.024 *$ & & & & & \\
\hline \multicolumn{7}{|l|}{ spatial } \\
\hline spatial(t-1) & $0.357^{* *}$ & & & & & $-0.810^{* * *}$ \\
\hline spatial(t-2) & & $0.294 * * *$ & & & $0.199 * *$ & $0.323 * * *$ \\
\hline spatial(t-3) & & & & & & $0.279^{* *}$ \\
\hline spatial(t-4) & $0.212 * *$ & $0.349 * * *$ & & & & $1.139 * * *$ \\
\hline spatial(t-5) & $0.472 * * *$ & & & & & \\
\hline \multicolumn{7}{|l|}{ spatial(t-6) } \\
\hline \multicolumn{7}{|l|}{ spatial(t-7) } \\
\hline spatial(t-8) & & & & & & \\
\hline
\end{tabular}


Table A2: Estimates of Models for State Incomes (Part II:B)

\begin{tabular}{|c|c|c|c|c|c|c|}
\hline State & North Carolina & Oklahoma & Texas & Virginia & Washington & Wyoming \\
\hline $\begin{array}{c}\text { Transition } \\
\text { Variable }\end{array}$ & $o(t-4)$ & $o(t-3)$ & $o(t)$ & $o(t-8)$ & $o(t)$ & $\mathrm{o}(\mathrm{t}-7)$ \\
\hline \multicolumn{7}{|c|}{ Nonlinear Part } \\
\hline Constant & $-0.012 * * *$ & & $-0.007 * * *$ & -0.001 & 0.002 & $0.009^{*}$ \\
\hline $\mathrm{y}(\mathrm{t}-1)$ & $0.402 * *$ & & $0.327 * * *$ & & & \\
\hline$y(t-2)$ & & & $-0.315^{* *}$ & & & \\
\hline $\mathrm{y}(\mathrm{t}-3)$ & & & & 0.440 & & \\
\hline$y(t-4)$ & & $-0.988 * * *$ & & 0.522 & $-1.326^{* * *}$ & \\
\hline$y(t-5)$ & -0.206 & & & $-2.392 * * *$ & & \\
\hline \multicolumn{7}{|l|}{$y(t-6)$} \\
\hline \multicolumn{7}{|l|}{$\mathrm{y}(\mathrm{t}-7)$} \\
\hline \multicolumn{7}{|l|}{$\mathrm{y}(\mathrm{t}-8)$} \\
\hline$o(t)$ & & & & $0.139 * *$ & $-0.071 * *$ & \\
\hline $\mathrm{o}(\mathrm{t}-1)$ & & $0.068 *$ & $0.103^{* *}$ & & & \\
\hline$o(t-2)$ & $-0.107 * * *$ & $-0.085^{* *}$ & & & & $0.0734 * * *$ \\
\hline$o(t-3)$ & & & & & & -0.099 \\
\hline \multicolumn{7}{|l|}{$o(t-4)$} \\
\hline \multicolumn{7}{|l|}{$o(t-5)$} \\
\hline \multicolumn{7}{|l|}{$o(t-6)$} \\
\hline \multicolumn{7}{|l|}{$\mathrm{o}(\mathrm{t}-7)$} \\
\hline \multicolumn{7}{|l|}{$\mathrm{o}(\mathrm{t}-8)$} \\
\hline$r(t)$ & -0.003 & & & & $-0.016^{* *}$ & \\
\hline \multicolumn{7}{|l|}{$\mathrm{r}(\mathrm{t}-1)$} \\
\hline $\mathrm{r}(\mathrm{t}-2)$ & & & & $-0.042 * * *$ & & \\
\hline $\mathrm{r}(\mathrm{t}-3)$ & $0.005^{*}$ & & & & & \\
\hline $\mathrm{r}(\mathrm{t}-4)$ & $0.017 * * *$ & & & & & $0.013^{* *}$ \\
\hline \multicolumn{7}{|l|}{$r(t-5)$} \\
\hline $\mathrm{r}(\mathrm{t}-6)$ & & & & & & -0.004 \\
\hline $\mathrm{r}(\mathrm{t}-7)$ & & $0.010 * *$ & $-0.004^{*}$ & & & $0.016^{* *}$ \\
\hline \multicolumn{7}{|l|}{$\mathrm{r}(\mathrm{t}-8)$} \\
\hline \multicolumn{7}{|l|}{$\mathrm{s}(\mathrm{t})$} \\
\hline $\mathrm{s}(\mathrm{t}-1)$ & & $0.110^{* * *}$ & $0.070 * * *$ & $-0.129 *$ & & \\
\hline \multicolumn{7}{|l|}{$\mathrm{s}(\mathrm{t}-2)$} \\
\hline \multicolumn{7}{|l|}{$\mathrm{s}(\mathrm{t}-3)$} \\
\hline \multicolumn{7}{|l|}{$\mathrm{s}(\mathrm{t}-4)$} \\
\hline \multicolumn{7}{|l|}{$\mathrm{s}(\mathrm{t}-5)$} \\
\hline \multicolumn{7}{|l|}{$\mathrm{s}(\mathrm{t}-6)$} \\
\hline $\mathrm{s}(\mathrm{t}-7)$ & & & & $0.347 * * *$ & & \\
\hline \multicolumn{7}{|l|}{$\mathrm{s}(\mathrm{t}-8)$} \\
\hline spatial & & & & & & \\
\hline spatial(t-1) & & & & & & $0.0689 * *$ \\
\hline spatial(t-2) & & $-0.658^{*}$ & & $0.291 * * *$ & & \\
\hline spatial(t-3) & $0.831 * * *$ & & & & & \\
\hline spatial(t-4) & $-0.688 * *$ & $0.729 *$ & & & & $-1.275^{* * *}$ \\
\hline spatial(t-5) & & & & & & \\
\hline spatial(t-6) & & & & & & \\
\hline spatial(t-7) & & & & & & \\
\hline spatial(t-8) & & & & & & \\
\hline gamma & $6.56^{* *}$ & $4.058 * *$ & 10.96 & $3.490 * * *$ & $4.236^{*}$ & $8.580 *$ \\
\hline$c$ & $-0.0426 * * *$ & $0.0334 * * *$ & $-0.0431 * * *$ & $-0.0702 * * *$ & $-0.0501 * * *$ & $-0.0138 * *$ \\
\hline$c 2$ & & & $0.0171^{* * *}$ & & & \\
\hline$\overline{R^{2}}$ & .5443 & .5374 & .4494 & .4291 & .2559 & .5306 \\
\hline AIC & -9.006 & -8.754 & -9.133 & -9.102 & -8.377 & -8.117 \\
\hline
\end{tabular}

Note: $* * *$ indicates $1 \%$ significance level; $* * 5 \%$ significance; * $10 \%$ significance. 